ARTIGOS 


\title{
JURISTAS: TEORIA SOCIAL E IDÉIAS POLÍTICAS
}

\author{
Fernando Correia Dias
}

Resumo. $\mathrm{O}$ artigo trata dos antecedentes da institucionalização das ciências sociais em Minas Gerais desde os anos 1940. Descreve também o ambiente intelectual de Ouro Preto ao fim do século XIX. Analisa ainda os textos dos juristas que abordam as idéias políticas relacionadas à teoria social. Por fim, evidencia a influência das tendências teóricas européias.

Palavras-chave: Teoria social, política, textos jurídicos, ciências sociais, Minas Gerais.

Está em andamento pesquisa nossa em torno da evolução das ciências sociais em Minas Gerais. Pretendemos obter visão de conjunto dessa área do saber, que englobe manifestações iniciais (antecedentes), a institucionalização acadêmica, o perfil biobibliográfico dos fundadores no âmbito universitário e o panorama das principais tendências da produção científica nos campos da sociologia, da antropologia e da ciência política. Neste texto se discorrerá acerca de um dos aspectos dos antecedentes.

Impõem-se, entretanto, certas anotações preliminares. Minas Gerais não contou, na segunda metade do século XIX, com núcleos de pensamento social, semelhantemente ao que ocorreu em outros pontos do território brasileiro: Recife e São Paulo, cujas Faculdades de Direito (suscitadoras desses estudos) datam de 1827; ou o Rio de Janeiro, cuja Escola Politécnica, impregnada pela doutrina positivista

Fernando Correia Dias é pesquisador junto à Universidade Federal de Minas Gerais. 
comteana, data de 1874. Ouro Preto, centro político desde os primeiros tempos da Capitania e importante pólo da rede urbana regional (situando-se entre as primeiras comarcas criadas), contava com escolas de caráter técnico, a de Farmácia (1839) e a de Minas (1875/76). Pode-se dizer que a elite política e intelectual que ali atua, no fim do século XIX, participando das campanhas abolicionista e republicana, assim como da Constituinte estadual de 1891, formou-se substancialmente na Faculdade das Arcadas (São Paulo); só em escala menor, nos estabelecimentos locais, no Recife ou na Faculdade de Medicina do Rio de Janeiro.

Predominam, na velha capital mineira, quanto a letrados, os elementos advindos da antiga e arraigada tradição do humanismo clássico. Eram quase sempre egressos dos educandários eclesiásticos: o Seminário de Mariana (1875), o Colégio do Caraça (1820) e o Seminário de Diamantina (1867). Neles hauriram, na etapa dos estudos de humanidades, conhecimentos que lhes ofereceram bases as respectivas formações profissionais e/ou intelectuais. Forjaram-se, desse modo, os juristas, filólogos, historiadores, professores (especialmente de línguas), parlamentares, escritores e jornalistas.

Notava-se ali extensa concentração de cultores do humanismo clássico, alguns dos quais dedicados especificamente às letras. Foi um tempo, a última década de Ouro Preto como capital (1887-1897), de fecunda vida intelectual, paradoxalmente em contraste com os sentimentos de desgosto, partilhados pela maioria da população, em face da iminência da mudança da sede do governo estadual para outra localidade, ameaça definida constitucionalmente e que logo se concretizaria. É a quadra em que criam instituições de indiscutível impacto na esfera da cultura: Ginásio Mineiro (1890), Imprensa Oficial (1891/92), Arquivo Público Mineiro (1895), além de ter ganho nova estrutura e nova força o Tribunal da Relação (1891). Pelos seus efeitos, ressalte-se, sobretudo, o aparecimento da Faculdade Livre de Direito (1892), da qual se falará mais adiante.

Nessa fase, em Ouro Preto, destacaram-se muitos homens ilustrados, alguns a um tempo intelectuais e políticos. Sobre eles e sobre como atuaram, dissertamos já em outro trabalho (Dias, 2001). No momento, por força de motivo concreto a esclarecer-se no final 
deste artigo, ressaltaremos apenas a figura de Afonso Arinos. Realizara, na cidade, quando adolescente, exames preparatórios; para Ouro Preto voltou depois de formado em Direito na capital paulista (1889), permanecendo na nova residência até 1896, quando empreende a primeira viagem à Europa. Teve atuação decisiva na comunidade por meio de várias iniciativas: como um dos mais animados fundadores da Faculdade de Direito (da qual foi secretário), como proponente da criação do Arquivo Público Mineiro, como professor de História da Civilização do Ginásio Mineiro e como principal promotor do acolhimento fraterno de escritores e jornalistas cariocas (inclusive Olavo Bilac) refugiados na capital de Minas por estarem sendo perseguidos por Floriano Peixoto em 1893.

Francisco Iglésias, no fundamental texto introdutório à quarta edição da História antiga das Minas Gerais, de Diogo de Vasconcelos, comenta a penúria da historiografia mineira voltada para a análise da situação regional. Discute o lugar comum antigo, segundo o qual o mineiro se dirige sempre à reflexão e à pesquisa. É afirmativa inverídica, pelo menos quanto à realidade social. Opõe objeção à prática do psicologismo aplicado ao exame do caráter nacional.

Discorrendo sobre o mineiro, afirma:

A auto-reflexão explicaria a pujança da criação artística, na pintura e escultura, na música, na ficção e na poesia. Se tem contribuído para enriquecimento desse universo, de pouco lhe valeu para a análise do real, como se vê na pobreza da produção sociológica ou historiográfica, quando Minas perde alto para São Paulo, Rio Grande do Sul, Pernambuco, talvez outras áreas, muito mais completamente estudadas. Minas, como conhecimento objetivo de seus problemas, perde para várias regiões, algumas bem menos ricas e influentes. (Iglésias, 1999, p. 14)

Não é o caso, a nosso ver, de completa inexistência de estudos; antes, de exigüidade e pouca abrangência deles. No Manual bibliográfico de estudos brasileiros, conhecida publicação, registramse vários trabalhos mineiros ou sobre Minas, notadamente etnográficos, que apreciaremos no levantamento das ciências sociais vigentes na região (Morais e Berrien, 1949). 
A opinião, acima registrada, do saudoso historiador mineiro, foi emitida em 1974, quando da terceira edição do livro prefaciado. Nas últimas décadas, o panorama se modificou sensivelmente com os resultados das pesquisas havidas nos programas de pós-graduação em Ciência Política, Sociologia e História. O próprio Iglésias, em artigo de que tivemos notícia, reconheceu os novos rumos: a região está sendo competentemente estudada sob o aspecto da realidade históricosocial. Esperamos com certeza que nossa pesquisa revelará a boa qualidade e o volume significativo dessa produção científica recente.

O ponto de vista de Iglésias, entretanto, desperta uma associação: em Minas não houve, no tempo devido, isto é, na passagem do século XIX para o XX (ou logo depois) nenhum pensador social do porte, por exemplo, de Silvio Romero, Pontes de Miranda, Alberto Torres, Oliveira Viana ou Pereira Barreto. Estiveram presentes apenas letrados dos tipos aludidos acima. Estamos investigando, inclusive por meio de discussão com colegas, as razões dessa ausência. Houve uma personalidade cujos interesses temáticos - no sentido da busca do conhecimento abrangente do Brasil - o faziam aproximar-se um pouco dos pensadores lembrados: foi Pandiá Calógeras; embora nascido no Rio de Janeiro, integrou-se completamente na vida intelectual e política de Minas, que ele representou no cenário da União. Era, porém, mais propriamente esclarecido historiador e atilado analista da realidade administrativa, sendo ainda eficiente executivo - e menos um pensador social. Destinado à análise de sua atuação, existe importante estudo produzido pelo próprio Iglésias (Iglésias, 1987).

Há vários temas atraentes para estudo no quadro da história das idéias em Minas Gerais. Mencionaremos apenas um deles, a que talvez nos dediquemos. Mereceria atenção, ao se considerar o evoluir do significativo pensamento sociopedagógico mineiro, dentro das sucessivas configurações da estrutura social da região, a análise do vínculo entre escola e comunidade: que propostas partiram dos educadores/administradores e que projetos se executaram? Poderia uma investigação dessa natureza abranger, por exemplo, desde a reforma do ensino de Afonso Pena (1892) até a atividade do Centro Regional de Pesquisas Educacionais João Pinheiro.

Por ora, na garimpagem a que estamos procedendo, na pesquisa sobre as ciências sociais em Minas, tivemos uma revelação. 
Encontramos alguns textos de juristas preocupados com a compreensão da vida humana coletiva, em geral de um ponto de vista teórico. Aplicaram a seus comentários conceitos e doutrinas aprendidos nos estudos realizados na Faculdade de Direito de São Paulo. Verificamos depois que dois desses escritos são mencionados também por Vamireh Chacon (Chacon, 1977, p. 43 e 87).

A fundação da Faculdade Livre de Direito do Estado de Minas Gerais representou um dos primeiros frutos, no campo intelectual, da proclamação da República.

Havia um decreto federal, de 2 de janeiro de 1891, que permitia a criação, por iniciativa privada, de estabelecimentos de ensino superior, com a condição de que preenchessem as exigências regulamentares necessárias à outorga da equiparação. A promulgação da Constituição de 1891 conferiu autonomia aos estados-membros, dando-lhes competência legal e recursos para muitas realizações.

Historiadores que tratam do evento da Faculdade acentuam que a República promoveu essa descentralização administrativa, de modo a incentivar as iniciativas dos governos regionais e locais, assim como os empreendimentos particulares, dificultados até então pelo caráter centralizador do regime monárquico. ${ }^{1}$

Logo após a proclamação da República, o historiador Diogo de Vasconcelos, diretor do Jornal de Minas, de Ouro Preto, sugeriu a idéia de criar ali uma academia jurídica. Combinou-se a iniciativa com a de outras pessoas, de tal forma que a idéia encontrou a melhor acolhida nos meios jurídicos da cidade e do estado (Arinos, 1895, p. 142). ${ }^{2}$

Ouro Preto era sede do Tribunal da Relação e contava com um grande número de juristas, alguns de renome nacional. O próprio presidente do estado, Afonso Augusto Moreira Pena, era "doutor em Direito, e um dos membros da comissão que, nos últimos dias do Império, fora encarregada de organizar o código civil brasileiro" (Escorço histórico, 1930, p. 219). Ao prestígio do governante, somou-se o esforço de muitos advogados, do que resultou a fundação da Faculdade, instalada solenemente no dia 10 de dezembro de 1892. Essa reunião foi precedida de encontros preparatórios, nos quais se tomaram as providências necessárias à organização do estabelecimento. $\mathrm{O}$ secretário interino, na fase inicial, era o escritor Afonso Arinos. 
Eis a primeira distribuição das cadeiras da Faculdade:

\section{CURSO DE CIÊNCIAS JURÍDICAS}

$\mathbf{1}^{\mathrm{a}}$ série

$1^{\text {a }}$ Cadeira - Filosofia e História do Direito

Antônio Augusto de Lima.

$2^{\text {a }}$ Cadeira - Direito Público e Constitucional

Sabino Alves Barroso Júnior.

$2^{\text {a }}$ série

$1^{\text {a }}$ Cadeira - Direito Romano - Gomes Rebelo Horta.

$2^{a}$ Cadeira - Direito Civil:

$1^{a}$ Cadeira - Antônio Gonçalves Chaves.

$2^{\text {a }}$ Cadeira - Virgílio Martins de Melo Franco.

$3^{\text {a }}$ Cadeira - Direito Comercial:

$1^{\mathrm{a}}$ Cadeira - Donato J. da Fonseca.

$2^{\mathrm{a}}$ Cadeira - Henrique de M. Sales

$4^{\text {a }}$ Cadeira - Direito Criminal - Afonso Arinos de Melo Franco.

$3^{\text {a }}$ série

$1^{\text {a }}$ Cadeira - Medicina Legal

Dr. Francisco Silviano de Almeida Brandão.

$4^{\text {a }}$ série

$1^{a}$ Cadeira - História do Direito Nacional

Camilo A. Maria de Brito.

$2^{\text {a }}$ Cadeira - Processo Criminal, Civil e Comercial Levindo Ferreira Lopes.

$3^{\text {a }}$ Cadeira - Noções de Economia Política e Direito Administrativo - Bernadino Augusto de Lima.

$4^{\mathrm{a}}$ Cadeira - Hermenêutica Jurídica e Prática Forense Joaquim de I. de Melo e Souza Jiquiriçá.

\section{CURSO DE CIÊNCIAS SOCIAIS}

Direito das Gentes, Diplomacia e História dos Tratados João Pinheiro da Silva. 
Economia Política - David Moretzsohn Campista.

Higiene Pública - Eduardo Augusto Montandon.

Ciência da Administração e Direito Administrativo

Francisco Luís da Veiga.

Ciências das Finanças e Contabilidades do Estado Afonso Augusto Moreira Pena.

Legislação comparada sobre o Direito Privado Antônio de Pádua A. Rezende.

Lentes substitutos: Alves de Brito, Teófilo Ribeiro, Teófilo Brandão, Adalberto Ferraz, Raimundo Corrêa e F. Catão.

Dos que foram designados a lecionar em 1892, três eram médicos, professores de Medicina Legal ou de matérias correlatas (Silviano Brandão, Francisco Catão e Eduardo Montandon); três se formaram em Recife, na Faculdade de Direito (Adalberto Ferraz, Henrique Sales e Teófilo Ribeiro); todos os demais diplomaram-se na Faculdade de Direito de São Paulo; esta tem, portanto, conforme já se assinalou, ponderável influência na formação intelectual da elite mineira. ${ }^{3}$

A instalação da Faculdade foi um acontecimento de relevo em Ouro Preto, sob a presidência de Afonso Pena. Discursaram 16 oradores, entre autoridades e representantes de estabelecimentos de ensino e outras instituições da cidade.

Seis anos depois, inaugurada Belo Horizonte, o estabelecimento se transfere para a nova Capital (1898). Era uma imposição das circunstâncias. Alunos e professores tinham que se mudar para Belo Horizonte, onde trabalhariam. Os magistrados, da mesma forma. Os advogados teriam maior campo, especialmente na segunda instância. Teve essa casa de ensino várias sedes provisórias, até que passou a funcionar, em 1901, em seu local definitivo, a hoje Praça Afonso Arinos. O novo prédio, construído há poucos anos, se levantou ao lado do antigo, que foi demolido.

Iniciativa relevante foi a da criação do órgão da faculdade. Chamava-se Revista da Faculdade de Direito do Estado de Minas Gerais. O primeiro número circulou em 1894. Nessa primeira fase, circularam onze números; a partir de 1949, lançou-se uma segunda fase. A revista publicava artigos, pareceres individuais, pareceres 
de comissões da congregação sobre códigos e projetos de códigos, quase tudo versando matéria jurídica. Há, porém, uma série de artigos dentro ou próximo da teoria social, e a respeito dos quais se falará mais adiante.

A revista tinha uma comissão de redação, quase sempre constituída de três professores. Eis a composição dessas comissões, com a data de edição: n. 1, 1894, Ouro Preto: João Pinheiro da Silva, Sabino Barroso Júnior e Antônio Augusto de Lima; n. 2, Ouro Preto: idem, idem, idem; n. 3, Ouro Preto: Tomás da Silva Brandão, Carlos Honório Benedito Otoni e Gastão da Cunha; n. 4, 1898, Belo Horizonte: Teófilo Ribeiro, Edmundo Pereira Lins e Estevão Lobo; n. 5, 1899, Belo Horizonte: idem, idem, idem; n. 6, 1901, Belo Horizonte: Camilo Augusto Maria de Brito, Francisco Mendes Pimentel e João Luís Alves; n. 8, 1906, Belo Horizonte: Antônio Augusto de Lima, Camilo Augusto Maria de Brito e Estevão Leite Magalhães Pinto; n. 9, 1914, Belo Horizonte: Edmundo Pereira Lins, Virgílio Martins de Melo Franco e Afonso Pena Júnior; n. 10, 1917, Belo Horizonte: Afonso Pena Júnior, Francisco Brant e Gudesteu de Sá Pires; n. 11, 1929, Belo Horizonte: Lincoln Prates, José Eduardo da Fonseca, José de Magalhães Drummond e Pedro Mata-Machado; o redator era Lincoln Prates.

A apresentação da revista foi feita por intermédio de um editorial de seis páginas assinado por Afonso Pena. Mostra estar a par das transformações pelas quais passava o mundo de então, ressaltando o papel dos estudos jurídicos na solução dos problemas emergentes.

O direito acompanha o evoluir das civilizações. No mundo moderno, com as inovações técnicas como o vapor, a eletricidade e o telégrafo, as relações sociais tornam-se mais intensas e complexas.

Depende a organização do Estado das normas jurídicas e absorve o empenho dos juristas. "O bem estar dos povos é preocupação dos governantes, nos tempos hodiernos. Não se trata de pesquisas teóricas, de discussões acadêmicas, e sim de uma ciência positiva, prática" (Pena, 1894, p. 5).

A ascensão das massas trabalhadoras nos países adiantados provoca novas discussões e soluções que repercutem aqui. Por sua vez, o Brasil vive em período de reconstrução política e administrativa, o que exige a renovação do direito. As velhas fórmulas do sistema jurídico português se tornam obsoletas. As faculdades livres constituem 
sintoma de que os particulares investem seus esforços em iniciativas altruísticas. E estas têm encontrado apoio popular.

Minas, a mais populosa e das mais extensas unidades federativas, precisava ter sua Faculdade de Direito para evitar que os seus filhos continuassem a buscar a oportunidade de estudos além de suas fronteiras. A implantação do estabelecimento foi tarefa espinhosa e arriscada, mas o empreendimento já começa a dar os primeiros frutos sazonados.

Será a revista o instrumento - como nos países avançados - do pensar e da informação jurídica. "Esta julgar-se-á bastante feliz se o resultado de seus esforços corresponder aos nobres intuitos que nutre de contribuir, ainda que pouco, para o progresso dos estudos jurídicos no Brasil" (ibidem, p. 8).

Sabino Barroso escreve, no primeiro número da revista, um ensaio sobre o tema da liberdade. Diz ser sempre oportuno o assunto, embora pareça muito conhecido. ${ }^{4}$

Ao longo do texto, coloca esse conceito no centro das considerações sobre a vida social. Recorda as teorias, a legislação e a ciência, as vivências refletidas dos patriotas e a dos oprimidos de todas as sociedades, tudo em busca da concepção de liberdade.

Na sociologia, como nas demais ciências, os erros são inevitáveis, mas os fenômenos sociais estão sempre presentes, devendo ser conhecidos pela aplicação constante dos trabalhos de observação e especulação. Mais adiante, lembrará a complexidade do conhecimento sociológico.

As concepções errôneas do passado constituem lições: são vias a não serem mais percorridas. Compara a contribuições do pensamento medieval, "absurdas ficções" daquela época, com os recentes avanços científicos que levam à certeza, dentre os quais as propostas de Darwin e Haeckel. "Aí estão atestando de modo irrecusável como é dado ao espírito humano, devassando os segredos do universo, determinar a lei de seus fenômenos" (Barroso, 1894, p. 80).

Cita uma série de filósofos de várias épocas, para argumentar com o insucesso das respectivas teorias. O direito, afirma, tem um desenvolvimento vagaroso e demorado; o problema da liberdade encontra-se aberto à solução sob vários aspectos. 
Acrescenta os aspectos das oscilações psicológicas, bem como do fluxo e refluxo, através dos tempos, dos momentos de absolutismo e vigência dos regimes livres. Nesse processo “intervém a ação oficial dogmatizando instituições no interesse dos que governam, sacrificando a ciência e a liberdade aos preconceitos do passado e aos caprichos do poder" (Barroso, 1894, p. 88).

Mas as pacientes investigações de Haeckel, Letourneau, Espinas, Schoeffle e principalmente Spencer, aplicando na teoria social o método experimental, concluem pela subordinação da sociedade à lei da evolução, que é a lei cósmica universal.

De acordo com esta concepção que racionalizou a teoria social, constituindo a sociologia sobre as bases das ciências experimentais, a sociedade se nos apresenta como um organismo e a liberdade como a sua lei. (ibidem, p. 89)

Discorre depois sobre o pensamento de Spencer em defesa da salvaguarda dos direitos individuais para o bom funcionamento da sociedade. A vida em sociedade depende da vida do indivíduo, pressupondo o homem coletivo o homem individual.

Mas a vida do indivíduo consiste no maximum de intensidade de suas forças ou faculdades que resumem todas na força ou no poder de escolher os meios de progredir, isto é, na liberdade.

A sociedade é assim um elemento de expansão das atividades individuais subordinada à lei da coexistência e harmonia; é um meio indispensável ao desenvolvimento das faculdades ou forças em que se desdobra a liberdade.

Assim se vê como é a liberdade a lei da organização social. (ibidem, p. 90)

Barroso mostra-se um spenceriano fiel; cita, por exemplo, a propósito das ciências, os termos inorgânico, orgânico e superorgânico. Assimilou do sociólogo inglês o espírito individualista, além do evolucionismo.

Na parte final do texto, procura demonstrar como as concepções científicas da vida social suplantaram os antigos modos de pensar teocráticos e metafísicos.

Citando Humboldt, lembra que a curva ascendente do progresso experimenta inflexões negativas em que se produz o sofrimento. Para 
o autor, vivia-se então um momento com essas características. Analisa severamente o exercício do poder com supressão das liberdades. Mostra a falta de preparo científico dos governantes.

Não injurio nem quero fazer referência pessoal a alguém; quase me sirvo de palavras textuais de emérito escritor contemporâneo para expor conviçção própria, filha do estudo imparcial dos acontecimentos políticos do nosso e dos países estrangeiros.

Seja como for o que não se pode contestar é que a causa da liberdade não venceu ainda em toda linha, para servir-se da expressão consagrada; ela sustenta sua nobre luta contra os inimigos que a combatem, contra os falsos apóstolos que a mitificam e até contra os próprios amigos que a desconhecem. (ibidem, p. 92)

O biógrafo de Sabino Barroso, Sebastião Pimenta Barroso, sustenta o ponto de vista de que esse artigo não se escreveu apenas com fins doutrinários. Era uma reação ao governo Floriano Peixoto, no poder na época, que estabelecera sérias restrições às liberdades políticas. Assim, o texto, bem fundamentado, teria endereço certo: era uma forma de opor-se às arbitrariedades do segundo presidente do governo provisório (Barroso, 1997, p. 106-107).

Augusto de Lima ${ }^{5}$ oferece um longo ensaio intitulado "Estudos Sociais", nele examina a afirmação, especialmente nas sociedades complexas, dos princípios do direito e da moral. Como ementa a seu texto, coloca o seguinte: "A luta pela vida, em relação ao direito e à moral, não é somente origem e meio; é também consequiência, como condição essencial para a conservação e o desenvolvimento" (Lima, 1894, p. 61).

A luta pela vida é um tema central do escrito. Para propô-lo, estabelece analogia - no caso do direito e da moral - com os organismos vivos, com o surgimento das manifestações da vida.

Demonstra o autor estar em dia com a ciência desse tempo, dando notícias das revelações da paleontologia, da cosmologia, da geologia e da astronomia, tudo isso para inferir que, no domínio que lhe interessa, não se carece também de um princípio vital exterior como explicação.

Aliás, começa o escrito com uma lembrança da Darwin:

Cremos poder repetir, com relação ao direito e à moral, o que o profundo naturalista Carl Vogt disse da origem das espécies, a 
propósito da doutrina darwiniana: "Ninguém mais, na Europa, ousa sustentar a sua criação independente". (ibidem, p. 61)

Depois de muitas considerações, Augusto de Lima faz um bom resumo de texto de um autor a quem chama de "ilustre sábio alemão":

O direito e a moral, diz Schäffle, são normas socialmente estabelecidas, reguladas sob as condições históricas da conservação social coletiva, formadas com a experiência do bem e do mal, impostas com coação externa pelos órgãos do poder, historicamente firmados e com coação interna pela força do espírito do povo, consolidadas pela transmissão hereditária e pelo costume: normas que dirigem a conduta, conservando e desenvolvendo, regulam as decisões da luta pela vida e pelos interesses, asseguram e circunscrevem as conseqüências da vitória e da queda nessas lutas e, em síntese, equilibram as ações que se manifestam na evolução social. (ibidem, p. 67)

A essa conceituação acrescenta outros elementos, insiste na importância da conservação e do desenvolvimento. Diz que não se busca visualizar e estabelecer uma situação caracteristicamente de paz, mas de luta. Esse combate básico pela vida tem suas normas estabelecidas pelas instituições, normas essas que devem levar à legitimidade das ações e à ausência do aniquilamento. Procura-se antes a vitória dos mais fortes.

O direito não é previamente estabelecido, porém impõe-se historicamente aos poucos; também as relações contratuais são estabelecidas pelas normas do direito e da moral.

Esclarece o autor as condições em que a conservação desses elementos dispõe de mais força.

As conclusões são spenciarianas:

É hoje uma verdade incontestável a afirmação de Spencer: um agregado homogêneo deve inevitavelmente perder sua homogeneidade pela exposição desigual de suas partes às forças incidentes (em First principles).

Este princípio compreende o organismo social em sua evolução.

Outra não foi a marcha seguida pela civilização a partir do amorfismo das primitivas agremiações até a constituição dos governos atuais.

A luta dos elementos heterogêneos de uma mesma massa deu origem a um modus vivendi; a um concerto, não de paz definitiva, 
mas de arregimentação de novas lutas fecundas de conservação coletiva e individual. Eis a origem do direito e da moral. (ibidem, p. 76)

Depois de outras considerações reforçando o argumento, declara:

A paz do direito como origem, como meio e como fim, é tão incompreensível como as idéias de bem absoluto, de causa primeira e de causa final, de que derivou.

Não: o direito e a moral vieram da luta, são sustentados pela luta e caminham para a luta.

É esta a lição da experiência. (ibidem, p. 76)

Deve-se assinalar que o cientificismo de Augusto de Lima, tão afastado nesse texto de toda idéia religiosa, iria dar lugar, no final de sua vida, a um cristianismo de timbre franciscano.

Coube a Estevão Lobo $\left(1869\right.$ - 1908) ${ }^{6}$, antigo deputado e professor de Filosofia do Direito, publicar na revista da faculdade, um texto sob o título de "Do organismo social".

Começa, na introdução, por fazer certas ironias, citando vários autores, a respeito da difusão, ao seu tempo, dessa doutrina.

O primeiro capítulo do artigo é destinado à exposição minuciosa dessa tendência sociológica; o segundo, à sua análise crítica. Os elementos para a construção do texto foram colhidos nos Annales de I'Institut Internacional de Sociologie (1898), dirigido por René Worms.

Firma-se a concepção fundamental em que todos os atos e fenômenos sociais têm um mesmo de partida: a vida. É ela a característica dos fatos que se passam na intimidade do indivíduo, assumindo outra animação e complexidade no mundo social. A estrutura, o funcionamento, a evolução dos seres coletivos, subordinam-se às mesmas leis que regem a estrutura, o funcionamento e a evolução dos seres isolados.

Compõe-se a sociedade de indivíduos, como estes de células; tais são a unidade econômica, social, jurídica e política, cumprindo atribuir-se a qualidade de célula ao ser individual e não à família. (Lobo, 1894, p. 6-7)

As unidades básicas são estabelecidas em todas as formas de agrupamento. A mais ampla é a nação. 
Dessas verificações, parte-se para a percepção da patologia social e da respectiva terapêutica, tal como se dá no mundo da vida individual.

René Worms afirma duas ressalvas. Não se proclama a identidade absoluta de sociedade e organismo e não se considera o organicismo como método exclusivo; as instituições da propriedade e da sucessão encontram-se sob o domínio de ordem puramente sociológica, embora se prendam a fatos vitais.

Lilienfield leva mais adiante a teoria: propôs um organismo pluricelular, real e concreto, que se forma de dois fatores: um sistema nervoso e uma substância intercelular.

Existem, assim, duas tendências básicas, dois subgrupos: a dos que defendem a homologia total entre os organismos e a sociedade e a dos que propugnam a simples analogia. Dentre os últimos se encontram Spencer, Huxley e Worms. O texto se interessa apenas pela segunda tendência.

Estevão Lobo lembra que o modelo organísmico não é tão novo como parece. Cita uma série de metáforas, desde a Antigüidade, que lembram as relações afins entre os seres vivos e a vida social.

Depois de outras considerações, o articulista recorre a Gabriel Tarde, o "lúcido espírito de Tarde". Para este, se apresentam duas preliminares: qual a necessidade científica da teoria? Qual a sua noção, o seu rudimentar conceito?

Vários autores têm tratado os temas sociais com êxito no mundo moderno - tornando-se alguns clássicos - sem recorrer à analogia organicista. Cita as contribuições econômicas de Adam Smith, a lei dos três estados de Saint-Simon e Comte; no campo da lingüística, as leis de Grimm e Raynuard, as da origem da família primitiva de Morgan e Mac-Lennan e as leis da arqueologia e direito comparado de Coulanges e Summer Maine.

Relativamente à segunda preliminar de Tarde, não lhe fica claro qual a especial sociedade que se compara ao organismo. Discute-se, por exemplo, se a nação ou o Estado.

Estevão Lobo examina uma por uma, cuidadosamente, as possíveis analogias, para recusá-las ou aceitá-las com muita restrição. Mostra em que a sociedade difere dos organismos vivos. Qual seria a célula: o indivíduo, o par, o trio? Há diferenças de sexos? Como se dá o crescimento? Como se dá o fenômeno da reprodução na colonização? 
E a divisão de trabalho? Como se distinguem as funções do cérebro das funções das elites? Que são os micróbios, como agem e como são acolhidos na realidade social?

Recorre de novo nosso autor a Tarde em busca de uma alternativa ao organicismo. Encontrara-a na visão psicologizante do famoso sociólogo francês.

Tarde mostra os méritos e as vantagens da psicologia coletiva que identifica com a sociologia. Evidencia como ela é mensurável e sujeita às medições estatísticas. Elucida o impulso da interação social. Não se interessa pelos fenômenos do eu isolado, mas do eu confrontado com o outro. Estevão Lobo faz um resumo preciso da contribuição desse autor.

A ação de uma pessoa sobre outra pessoa - eis o fato social elementar, perpétuo e universal; trabalha a vida por favorecer esse encontro fecundo, esse maravilhoso desenvolvimento intermental; para ele convergem todos os movimentos de nosso corpo, todas as contrações musculares - como pequenos gravetos na fogueira do nosso eu transfundidos em flamas sociais. (ibidem, p. 17-18)

O que Tarde mostra a Estevão Lobo, parece, é a formação da vida humana coletiva através do processo de socialização.

Apesar de todo o esforço em demonstrar a inverosimilhança de certas analogias propostas, o autor termina o seu trabalho com estas palavras:

Não há negar, porém, que a doutrina organicista, com o ser vaga e indeterminada, com o ser também perigosa por suas consequiências, de tal modo que Spencer já não lhe partidário extremado, prestou, não obstante, serviços assinalados à ciência, qual o notável auxílio aos naturalistas, e, no fundo de seu erro fundamental, a alma da verdade de ser o agregado social uma realidade sólida, um fenômeno natural por oposição ao apriorismo, dominante ainda em recente data, do contrato social e outras criações anticientíficas quanto à origem, índole e compreensão da sociedade. (idem)

Segue-se, dentre os textos de natureza sociológica publicados pela revista da Faculdade de Direito do Estado de Minas Gerais, a aula inaugural proferida por David Campista (1861-1911) ${ }^{7}$, famoso político mineiro. A preleção tem o título: "O Direito Público e a sua reconstrução 
científica" e o subtítulo: "Introdução ao estudo do direito público e constitucional”. De quantos estão sendo resenhados é o que traz maior número de citações eruditas.

A aula se prende, em especial, à análise do desenvolvimento então recente dos estudos sociológicos e da influência por eles exercida sobre as disciplinas jurídicas. Começa pelo campo em que mais cedo se revelou essa presença: o do direito criminal e da criminologia. $\mathrm{O}$ conferencista se refere principalmente a mestres italianos (mas não apenas a estes) e às modificações doutrinárias sofridas pelo ramo em foco.

Destaca o direito administrativo, seus progressos e o paralelismo que tem tido com os estudos sociológicos.

Discorre depois acerca do direito privado, em particular o comercial, mostrando como o ângulo sociológico do mesmo vinha sendo revelado. Diz que o direito público tem experimentado muito menor influxo da sociologia - e é no sentido de modificar tal estado de coisas que fará uma proposta. Em outra passagem do texto, comenta como o direito constitucional mostra-se órfão, ficando em situação de inferioridade, comparativamente a outros setores do conhecimento, nas mostras das livrarias e bibliotecas.

A economia política merece especial atenção em suas relações com a sociologia. Descreve as mudanças do mundo moderno no campo da produção, com transformações profundas na estrutura de classes. Isso vinha chamando a atenção dos pensadores como Karl Marx e Loria: para eles os fenômenos econômicos encontram-se no centro das preocupações sociológicas. "Para Marx - o modo de produção da vida material domina, em geral, o desenvolvimento da vida social, política e intelectual" (Campista, 1901, p. 61). Os fenômenos econômicos despertam preocupação generalizada. Conseqüência disso é o abandono a que se relega a ciência política propriamente dita, que parece vegetar.

Esse movimento de convergência entre as disciplinas jurídicas e as sociais se fez lentamente e foi-se consolidando. Manter-se-ão autônomos os dois ramos, não havendo risco de se confundirem. $\mathrm{O}$ direito, de prática diária no pretório, passou à arte e depois à ciência.

Campista traça o rumo da consolidação da sociologia como disciplina científica, espécie de síntese e coordenação das ciências sociais particulares, que age pela observação, pela classificação 
dos fenômenos e pela indução. Generaliza e estabelece leis, tendo o seu método próprio. Ele não se impressiona com as críticas aos sociólogos, acusados de divergências insanáveis e de diversidade metodológica. Deseja oferecer fundamento científico para o ramo do direito que cultiva.

Exatamente em virtude da complexidade dos seu objeto é que o direito político deve beber a sua orientação na larga fonte de uma ciência que estuda, observa e classifica os fatos sociais nos seus grandes caracteres gerais. (ibidem, p. 70)

Para a reconstrução que se propõe, leva em conta o método jurídico e o sociológico e, subsidiariamente, ligado ao primeiro, o método dogmático.

Citando Labauld, afirma que método jurídico consiste no seguinte processo:

Em presença do sistema constitucional de um país, deve-se: $1^{\circ}$, analisar as relações jurídicas que constituem o seu direito público; $2^{\circ}$, estabelecer-se precisamente a natureza jurídica de tais relações; $3^{\circ}$, por um movimento ascensional de generalização - descobrir os princípios jurídicos mais gerais a que são elas subordinadas; $4^{\circ}$, enfim, por um movimento contrário, deduzir dos princípios descobertos as consequiências que deles decorrem porque uma vez obtidos os princípios gerais é preciso desenvolver as suas consequiências. (ibidem, p. 78)

Esse processo, na verdade, oferece muitas dificuldades em sua aplicação.

O que o autor propõe é o uso, de preferência, do método sociológico para a reestruturação do direito público, mas sem desprezar de todo o método jurídico.

A escola jurídica não pode porém ser todo abandonada na ciência de que tratamos. "O direito constitucional, diz Majorana, é sem dúvida matéria social e política, mas também jurídica e o direito tem aqui uma grande importância formal. A técnica constitucional é essencialmente jurídica. Se o objeto desse direito é filiado às mais largas determinações sociais e políticas, o modo prático de traduzilas em ato é pelo direito. (ibidem, p. 80) 
No mais, ressalvados parênteses em que se discutem o método dogmático e as perspectivas comparativa e histórica, todo o texto é em favor da aplicação da sociologia ao direito público.

Não tratamos, porém, de estudar aqui o método que deva adotar a sociologia geral e sim a vantagem de aplicação dos processos sociológicos ao estudo do direito público que assim se libertará do dogmatismo jurídico ou metafísico. (ibidem, p. 86)

Considerando esse ramo jurídico em suas relações, em seu conteúdo, em seu objeto, verifica-se que se trata de um campo aberto à sociologia.

E assim se faz esse estudo sociológico. Primeiro das fontes do direito: a lei, os usos e costumes. Depois, os sujeitos do direito, especialmente em sua relação com o Estado. Mais adiante, a opinião pública e suas manifestações. Por fim, o conceito de soberania, tomado entre outros nesse campo do conhecimento.

O trabalho de David Campista é extremamente erudito e bem concatenado. É um texto denso, do qual damos apenas uma notícia. Os principais sociólogos da passagem do século são citados nessa aula, com exceção apenas de Max Weber, que não começara ainda a ser divulgado fora da Alemanha.

Como encarar essas tentativas de discutir questões de teoria social? Como esforços louváveis para transpor os limites do conhecimento estritamente jurídico. No caso de David Campista, veja-se em sua aula inaugural intento bem sucedido no campo epistemológico, graças ao bom nível de informação revelado. Os demais escritos assumem quase a função de testemunhos de uma aprendizagem, de tendência cientificista, feita em São Paulo. Augusto de Lima e Estevão Lobo foram professores de Filosofia do Direito, habituando-se a discutir fundamentos teóricos da ordem jurídica e social. Sabino Barroso revela motivação política em seu artigo. Assinale-se que, dos autores estrangeiros citados nos referidos escritos, alguns permanecem ainda hoje como referências válidas, enquanto outros se perderam no completo olvido.

O cientificismo, adotado por muitos mestres brasileiros no final do século XIX, é objeto de criteriosa análise por parte de Roque Spencer Maciel de Barros, num livro clássico; estuda-o a par de duas outras 
tendências então vigentes: o liberalismo e o catolicismo tradicional (Barros, 1986, p.25-203).

Fora dos casos dos professores da Faculdade de Direito, e para citar apenas um autor de posição católica, lembremos o ensaio do historiador Diogo de Vasconcelos (1843-1927), "Resumo da história da arquidiocese de Mariana", publicado em 1928. É uma narração objetiva da posse e da ação dos sucessivos bispos marianenses, desde o século XVIII, com destaque para D. Viçoso e D. Silvério. ${ }^{8}$

Assinala-se ainda que houve, em Minas, o antipositivismo; é o caso do antigo presidente Raul Soares de Moura, que, na mocidade, escreveu textos contrários à doutrina de Augusto Comte (Renault, 1979).

Lembre-se agora a existência de um precursor da sociologia. Trata-se de Augusto Franco (1877-1909), diplomado em Direito em 1907, e que escreveu sobre essa matéria mais amiúde. Publicou os textos de suas provas na Faculdade e discorreu sobre assuntos de método e de teoria social. Discípulo entusiasta de Silvio Romero, tomou o partido deste nas polêmicas mantidas com outros autores, principalmente com José Veríssimo. Exerceu a crítica literária no Minas Gerais, órgão oficial do estado, sendo, nesse terreno, partidário de Taine. Seu principal livro, sob o ponto de vista que aqui nos interessa, é Estudos e escritos: esboços e crônicas (Franco, 1906). Sobre o autor podem ser lidos comentários críticos em Eduardo Frieiro (Frieiro, 1955) e Fábio Lucas (Lucas, 1965). Augusto Franco, germanista convicto, faleceu em Friburgo, na Alemanha. Era o representante, em Minas, da influência da Escola do Recife.

Mencionem-se dois trabalhos desse precursor. O primeiro chamase "Uma argüição" e tem como subtítulo: "Origem, elementos, estrutura e evolução da sociedade. Concepção mecânica e orgânica”. É uma prova redigida na Faculdade de Direito e que o autor expôs oralmente depois, sendo taquigrafada. Cita, inicialmente, o sociólogo alemão Rudolf Eisler, cuja divisão da sociologia, bastante minuciosa, nosso autor transcreve. Discute o caráter científico da sociologia (invocando as opiniões, respectivamente, contrária e favorável de Tobias Barreto e de Silvio Romero); discute também as relações entre Estado e sociedade; trata dos grupos sociais e dos tipos de sociedade, da origem das sociedades humanas, da família como unidade social; examina as sociedades animais; com base nos pensamentos de Charles Darwin e H. Spencer, discorre sobre a origem da matéria, da força e do 
movimento, a origem da vida e a origem das faculdades espirituais do homem; discute, enfim, as concepções mecânica e orgânica da vida social. Outro autor mencionado é o próprio Silvio Romero. Augusto Franco faz numerosas citações em alemão, sem traduzi-las (Franco, 1906, p. 163-207).

Sobre Silvio Romero, na perspectiva do pensamento social brasileiro, é o outro trabalho que selecionamos. Compõe-se de duas partes: o prefácio que escreveu para o opúsculo do escritor sergipano denominado Passe recibo (réplica a Teófilo Braga, publicado pela Imprensa Oficial de Minas, 1904); e uma série de tópicos sobre os Discursos, livro de Silvio Romero editado também em 1904. A primeira parte consiste num ensaio sobre a personalidade e a obra do autor de Contos populares do Brasil; o tom é invariavelmente elogioso e o ensaísta toma sempre a defesa de seu mestre; há apenas uma divergência quanto a certa interpretação de Taine; a segunda é o exame dos discursos proferidos no Congresso Nacional, em que Silvio Romero representou Sergipe e de que foi depois afastado por manobra escusa.

As referências a Silvio Romero perpassam toda a obra de Augusto Franco, que é numerosa. Pode-se ler, por exemplo, em Fragmentos literários, um texto a respeito. $\mathrm{O}$ crítico mineiro recebera, com carinhosas dedicatórias, dois livros do sergipano: um ensaio crítico denominado Martins Pena e os Ensaios de sociologia e literatura. Faz a resenha de ambos, com extremo cuidado de dar ao leitor uma perspectiva fiel do conteúdo dos textos, a par de opiniões elogiosas. Nesse esforço, transparece o interesse sociológico.

Sobre a questão imigratória, tratada por Silvio Romero, diz:

Seguindo, mais ou menos, o processo dos modernos resenhistas ingleses e americanos, darei aos leitores uma idéia ligeira, um rápido bosquejo desse esplêndido trabalho, página que, ela só, vale por todo um admirável programa para a solução definitiva de tão complicado problema social e etnológico. (Franco, 1904, p. 35)

É preciso fazer referência, neste capítulo, a dois destacados juristas nascidos e criados na província de Minas Gerais: Lafayette Rodrigues Pereira (1834-1917) e Pedro Augusto Carneiro Lessa (1859-1921). O primeiro nasceu numa fazenda localizada na freguesia de Nossa Senhora da Conceição, que é hoje a cidade de Conselheiro Lafaiete, antiga Queluz. Pedro Lessa nasceu na cidade do Serro, berço de muitos 
mineiros ilustres. Ambos, entretanto, desenvolveram carreiras profissionais, em grande parte, fora de Minas.

Tinham um traço em comum. Alfredo Bosi, no capítulo "A consciência histórica e crítica", de sua História concisa da literatura brasileira, refere-se a personagens dos anos 1870 e seguintes. Cita: "Clóvis Bevilacqua, Laffayette Rodrigues Pereira e Pedro Lessa, juristas de sólida doutrina e gosto pelo fenômeno literário" (Bosi, 1974, p. 274).

Lafayette formou-se em 1857 na Faculdade de Direito de São Paulo. Exerceu, por algum tempo, a promotoria em Ouro Preto. Em 1860, transfere-se para o Rio de Janeiro, para ser advogado e brilhante jornalista. Fez carreira política, como presidente das províncias do Ceará (1864-1865) e do Maranhão (1865-1866) e como deputado geral (18781880). Apesar de haver subscrito o manifesto republicano de 1870 , voltou ao seio do partido liberal, sob cuja égide organizou e presidiu o Gabinete entre maio de 1883 e julho de 1884, exercendo, simultaneamente, o cargo de ministro da Fazenda.

Foi senador pela província de Minas Gerais e também conselheiro do Império. Destacou-se como jurista, elaborando pareceres, publicando compêndios e presidindo a comissão designada para opinar sobre o projeto de Código Civil. Tomou parte em tribunal arbitral que tratou de controvérsias entre Chile, Peru e Bolívia.

Encontrava-se no México, como participante da I Conferência Interamericana, quando a República foi proclamada. Desligou-se dessa missão e viajou para a França, onde viveu por dois anos (Monteiro, 1994, p. 529).

Com o pseudônimo de Labieno, o jurista mineiro polemizou com mais eminente sociólogo brasileiro da passagem do século: Silvio Romero. Trata-se do livro Vindiciae, com o subtítulo de "O sr. Silvio Romero crítico e filósofo". A edição é de 1899 e reúne dois ensaios: "Machado de Assis. Estudo comparativo" e "Ensaios de Filosofia de Direito". Os dois livros criticados apareceram, respectivamente, em 1897 e 1895 . Os textos críticos apareceram primeiramente na imprensa e foram duramente atacados pelo escritor sergipano. Ele havia comparado, como poetas, Machado de Assis e Tobias Barreto, negando ao primeiro essa condição e exaltando os escritos do segundo. Lafayette faz uma veemente defesa do escritor de Dom Casmurro, pondo em relevo sua estética apurada (Labieno, 1934). 
Vindiciae teve mais duas edições. Foi novamente publicado, em 1934, no centenário de Lafayette, pela sociedade "Os amigos do livro", de Belo Horizonte, por iniciativa de Eduardo Frieiro e com introdução de Mário Matos. Em 1940, saiu pela Livraria José Olympio.

Cabe uma exposição bem mais extensa sobre Pedro Lessa, que manifesta um pensamento social constante e explícito. Foi, principalmente, um grande jurista e um notável juiz; distinguiu-se, entretanto, como escritor, em várias outras áreas do conhecimento.

Passou a infância e a adolescência na cidade natal do Serro. Fez ali parte de seu curso de humanidades, concluído em Vassouras, na província fluminense.

Matriculou-se na Faculdade de Direito de São Paulo, pela qual se bacharelou e se doutorou, respectivamente, em 1883 e 1884. Durante o curso, conduziu-se, sob os pontos de vista intelectual e político, à moda de vários de seus co-provincianos da época: participou da imprensa acadêmica, fez campanhas abolicionista e republicana, imbuiu-se das filosofias então influentes, como o positivismo comteano e o evolucionismo. Mais tarde, com relação ao positivismo, tornouse heterodoxo.

Pedro Lessa ligou-se, durante rápido período, ao Partido Republicano em Minas, aparecido em 1888. Foi designado juntamente com Joaquim Felício dos Santos e Ferreira de Resende, para elaborar o projeto da Constituição do futuro Estado de Minas Gerais.

Em julho de 1889, apresentou-se como candidato a deputado geral, pelo $18^{\circ}$ Distrito, porém não logrou eleger-se.

Fez uma incursão na política paulista: foi eleito deputado à Constituinte estadual, tendo nela desempenho de realce. A partir daí abandona as lides políticas, a fim de dedicar-se apenas às jurídicas.

Exerceu o cargo de secretario do Tribunal da Relação de São Paulo. Por concurso, foi nomeado professor da Faculdade das Arcadas. Era um mestre altamente estimado pelos estudantes, com cujos órgãos representativos se relacionou com cordialidade.

Em 1907, foi nomeado membro do Supremo Tribunal Federal, tornando-se um juiz que desfrutava de elevado conceito. A nomeação partiu de Afonso Pena; iria substituir Lúcio de Mendonça. Exerceu o cargo até o falecimento, 1921. 
Na carreira jurídica de Pedro Lessa, há dois aspectos eminentes. O primeiro é o do entendimento do instituto do habeas corpus como ferramenta válida para a defesa das liberdades públicas, em todos os casos, especialmente naqueles que envolviam as prerrogativas de imprensa e de opinião. Quando aplicava a lei com independência e calcada em excelentes fundamentos, o grande advogado era Rui Barbosa. Os votos de Lessa tiveram grande influência no sentido de se adotar essa concepção. Foram muito importantes nos momentos de crise política. O segundo aspecto é o de que renovou, oferecendo novos fundamentos doutrinários, o ensino da Filosofia do Direito.

O livro Discursos e conferências (1916) é de leitura indispensável para que se conheçam concepções do autor sobre a vida social. Nele ressalta o vivo interesse de Pedro Lessa pelos temas históricos. Fora ele acolhido como membro do Instituto Histórico e Geográfico Brasileiro em 1907. No ato de recepção, lê significativo discurso, em que examina as funções da instituição e a importância do papel intelectual do historiador.

Ocupados com a investigação dos fatos históricos, na verdade estais colaborando na formação das várias ciências, que procuram saber o que é a sociedade, que exigências têm reproduzido os seus fenômenos, para formularem as regras de conduta dos homens. Não conheço missão mais proveitosa, nem mais augusta. (Lessa, 1916, p. 39)

Fala ainda da profunda impressão que lhe causara a leitura dos relatos etnográficos de Von Martius, os quais lhe deram noções a respeito das relações jurídicas entre indígenas.

Encontram-se no mesmo volume duas competentes conferências nessa área do saber: a pronunciada na Sociedade de Cultura Artística, em São Paulo, em 1913, e em que realiza a análise do desenrolar da vida e das atividades de João Francisco Lisboa como jornalista e estudioso; e a proferida no IHGB, estudando minuciosa e criticamente a obra histórica de Francisco Adolfo Varnhagen.

Henry Buckle, historiador inglês, foi lido no Brasil, no fim do século XIX, pela elite letrada que se interessava pela temática das civilizações. Escreveu ele a História da civilização na Inglaterra.

A obra de Buckle foi traduzida do francês para o português e publicada em São Paulo. O segundo e o terceiro volumes foram 
publicados em 1899, os demais em 1900. O primeiro volume traz prefácio de Pedro Lessa, de que foi tirado em 1901 o folheto É a história uma ciência? Apesar de ser, como Buckle, partidário do determinismo, Lessa refuta a suas conclusões por negar à história o conteúdo científico pretendido pelo escritor inglês. (Enciclopédia Mirador, 4, 1981,p. 1822)

Como situar no campo teórico ou doutrinário? Exclui-se aqui a consideração estrita do âmbito jurídico. Tememos a proposta de Antônio Paim. Na introdução do volume que organizou, Plataforma política do positivismo ilustrado (Paim, 1981), inclui Pedro Lessa nessa corrente. Lembra e caracteriza vertentes positivistas que se estabeleceram no Brasil. Duas delas foram objeto de coletâneas da mesma série, publicada pela Universidade de Brasília. Fala do Apostolado Positivista, ao qual coube fazer circular a idéia da ditadura republicana, mas quem aplicou a noção de forma concreta, acrescenta, foi Júlio de Castilhos no Rio Grande do Sul. Confluíram as duas correntes para emergência do "autoritarismo doutrinário" (ibidem, p. 3).

No campo filosófico em foco, afirma, há outra concepção a considerar. É a vertente do positivismo ilustrado, que se opõe diametralmente ao autoritarismo, valorizando mais o lado educativo da obra de Comte: apela para as consciências. Privilegia, por esse motivo, a ação pedagógica. A reforma social decorre antes da mudança de mentalidade e das transformações dos costumes do que da ação política.

O autor relaciona, nessa direção, Luís Pereira Barreto, Alberto Sales, Pedro Lessa e, entre os contemporâneos, Ivan Lins. Acrescenta ainda o nome de Aarão Reis, que trata do intervencionismo econômico.

Pedro Lessa tornar-se-ia no Supremo Tribunal, o paladino da consolidação do habeas corpus, que a lei e a prática ainda não tinham elevado à condição de direito constitucional. Esse tema, como o das liberdades públicas, chegaria a ser talvez a principal bandeira do liberalismo republicano. De sorte que se pode dizer que os positivistas ilustrados vincularam sua sorte à do liberalismo. (idem)

Antônio Paim comenta o pensamento de Pedro Lessa, especialmente em suas raízes positivistas. E transcreve três textos dele: $\mathrm{o}$ discurso de paraninfo em 1906, na Faculdade de Direito de São Paulo, "O direito do século XIX" (1909) e o discurso na Associação Brasileira de Estudantes (Capital Federal, 11 de agosto de 1913). 
Destaquem-se dois temas que aparecem no pensamento social de Pedro Lessa. O primeiro é o de sua atitude claramente crítica ante o despreparo, inclusive intelectual, dos políticos brasileiros.

Um dos grandes males da República é a incontestável e revoltante inferioridade moral e intelectual dos chefes políticos. Assinalo aqui este fato, como os nossos outros defeitos públicos, não com o espírito partidário, que nunca fui, mas como mero estudioso dos fenômenos sociais, um imparcial perquiridor, aplicando o método científico da observação. Ora, não é uma perfeita necessidade querer abolir nossos defeitos, entregando escancaradamente, e sem corretivos, a nossa direção política precisamente aos cidadãos que são os maiores responsáveis pelo nosso estado presente, os principais causadores de nossas misérias sociais? Nem se diga que o sob o presidencialismo esses mesmos chefes dirigem o presidente da República, e governam indiretamente. Sabemos todos que o presidente da República, pesando sua grande responsabilidade, não raro se recusa à prática de atos prejudiciais e indecorosos, exigidos pelos chefes políticos. (Lessa, 1925, p. 41-42)

Assim se expressa no livro sobre a reforma constitucional, iniciativa à qual se opunha, por entender que esse processo, como o tem demonstrado a experiência de vários países, não resolve problemas políticos e institucionais. Discute a questão do parlamentarismo, que, a seu ver, não teria sucesso, no país, sem modificações no plano dos costumes políticos. Afirma que o sistema funcionou bem no Império, graças às qualidades pessoais de Dom Pedro II. Ao fazer o diagnóstico da realidade política brasileira, mostra-se pessimista em relação ao caráter e ao comportamento dos homens públicos (idem).

Pedro Lessa tinha, entretanto, em 1913, falado de modo esperançoso quanto à formação das elites, palavra que, aliás, não emprega.

O discurso que dirigiu aos estudantes, no Rio de Janeiro, no dia do aniversário de fundação de cursos jurídicos, isto é, a 11 de agosto, contém uma eloqüente e bem articulada análise de impositividade do adequado encaminhamento intelectual das pessoas destinadas à função pública. Ele contestava, com ardor, uma opinião, corrente na época, de que se poderia e até se deveria dispensar o preparo da inteligência para o exercício da vida pública. Faz o elogio do papel positivo desempenhado, no Brasil, pelos cursos jurídicos, aos quais se liga afetivamente. 
Nessa oração relembra, com ênfase, vários exemplos históricos, ao longo do evoluir civilizatório, de governantes que agiram com eficácia, atendendo às aspirações dos governados, mercê da capacidade de que se revestiam.

Refere-se ao Brasil, para citar alguns exemplos de vultos políticos que se destacaram na mesma linha. Menciona elogiosamente o caso da ação do Visconde de Ouro Preto, que agira com discernimento e eficiência, logo depois da abolição da escravatura, para propiciar crédito bancário acessível aos agricultores.

A mensagem dessa fala é a de que se impõe o recrutamento das verdadeiras capacidades para a ação governativa, sendo indispensável que as novas gerações se preparem desde cedo para ocupar condignamente os postos de liderança política (Lessa, 1916, p. 167-182).

Outro tema que nos atrai a atenção, no pensamento social de Pedro Lessa, é o referente a peculiar modalidade de socialismo, do qual se considera defensor.

Declara no texto sobre a realidade jurídica nos novecentos:

O século XVIII levou ao século XIX a preocupação da liberdade política, que durante longo tempo foi objeto da questão jurídica mais impolgante, mais incandescente.

O século XIX não espirou sem formular, para ser resolvida pelo século XX, um problema de ordem jurídica.

A organização atual da propriedade, resultado de uma lenta evolução de muitos séculos, porquanto acuradas investigações históricas e seguras induções nos mostram que nos tempos primitivos, assim como ainda hoje entre agremiações humanas rudimentares, dominava a propriedade comum da terra, tem sido rudemente combatida pelos sectários dos novos ideais econômico-jurídicos.

O socialismo, nome comum a todas as teorias que subordinam mais ou menos completamente o indivíduo ao Estado, e restringem mais ou menos a propriedade individual em benefício da propriedade coletiva, preconiza a necessidade de corrigir as desigualdades sociais. (Paim, 1981, p. 131)

Disserta sobre o anarquismo, utopia que descarta por completo, para afirmar que, "no sentido lato da expressão, o socialismo 
compreende o comunismo, o coletivismo e o socialismo propriamente dito" (ibidem, p. 132).

Depois de caracterizar as duas primeiras modalidades, discorre positivamente sobre a terceira:

O socialismo propriamente dito não alimenta a aspiração comunista de fazer todas as coisas propriedade comum de todos os homens, nem pretende abolir a propriedade privada sobre o capital, ou riqueza de reprodução. Sem extinguir a propriedade individual, quer atenuar quanto possível as desigualdades econômicas, invoca a ação do Estado, cuja intervenção os adeptos de todas as teorias socialistas reputam indispensável. (ibidem, p. 133)

Enumera uma série de providências imprescindíveis para amparar os operários e suas famílias, do ponto de vista da remuneração e das condições do trabalho, assim como da efetiva educação; a garantir os inválidos, as viúvas e os órfãos, além de propor um "um imposto progressivo, ou de qualquer modo pesado, sobre a herança e o luxo" (ibidem, p. 134).

O texto é de 1909; coloca-se na perspectiva do proletariado e antecipa preocupações que os poderes públicos só manifestariam, no Brasil, assim mesmo de forma tímida, vários anos depois, talvez influenciados pelo fato de o governo brasileiro ter sido signatário do Tratado de Versalhes (1919), que impunha medidas de salvaguarda de prerrogativas do trabalho.

É significativo este trecho do jurista:

Muitas das aspirações das várias escolas do socialismo propriamente dito hão de ser fatalmente concretizadas em leis. Não há um só homem de coração bem formado, que não sinta confrangido ao contemplar o doloroso quadro oferecido pelas sociedades atuais com sua moral mercantil e egoísta. O socialismo há de triunfar parcialmente. O seu triunfo é infalível, necessário.

Embora tenha passado grande parte de sua vida adulta fora de Minas, Pedro Lessa é identificado como um autor mineiro e cultivado nos meios jurídicos. Para dar apenas um exemplo, funciona, na Faculdade de Direito da UFMG, há muitas décadas, o Centro Acadêmico Pedro Lessa, o conhecido CAPL, prestigiosa agremiação de trabalho intelectual dos estudantes. ${ }^{9}$ 
O próximo passo, em nossa pesquisa, será o do estudo do ideário sociopolítico de Afonso Arinos. Estudaremos a memória histórica da Faculdade de Direito de Outro Preto (1895), a conferência a respeito da unidade nacional, proferida, em Belo Horizonte, em 1915 (data da grande seca do nordeste, de que deriva o romance $O$ quinze, de Raquel de Queirós) e mais alguns textos incluídos no livro Notas do dia (1900). A vinculação de seu nome e de sua obra à temática de Canudos será levada em conta. Isso exigirá que se amplie a leitura crítica, abrangendo-se os textos dos demais autores envolvidos no processo de compreensão do importante episódio histórico. ${ }^{10}$

\section{Notas}

1. Existe considerável bibliografia sobre a Faculdade de Direito fundada em Minas no ano de 1892. Selecionamos dois títulos: Arnaut, Luís Duarte Haele. Reinado do Direito (Minas Gerais 1892-1911) e Memória histórica. (Revista da Faculdade de Direito/UFMG).

2. A Memória Histórica escrita por Afonso Arinos contém expressivas considerações iniciais de interpretação da história de Minas e sobre a respectiva realidade educacional.

3. Escreveu-se toda uma crônica minuciosa da presença dos mineiros na Faculdade de Direito de São Paulo; veja-se notícia a respeito, por exemplo, no livro de Afonso Arinos de Melo Franco. Um estadista da República: Afrânio de Melo Franco e seu tempo. Rio de Janeiro: Editora Nova Aguilar, 1977, p. 160-186.

4. Sabino Barroso era também jornalista, tendo colaborado em periódicos do Serro e de Diamantina; é possível, segundo José Moreira de Sousa, estudioso da região, que neles tenha escrito artigos de caráter sociológico. Foi constituinte estadual de 1891, deputado federal e presidente da Câmara dos Deputados. 
5. Augusto de Lima, figura destacada da política mineira, estudou no Seminário de Mariana, onde cursou humanidades. Era poeta parnasiano bem aceito pela crítica, sendo que alguns viam em seus versos certo cunho "científico". Exerceu o cargo de governador de Minas (1891), dirigiu o Arquivo Público Mineiro e foi deputado federal por várias legislaturas.

6. Estevão Lobo, além de professor de Direito, foi deputado federal (1900-1905).

7. David Campista foi constituinte estadual em 1891, destacando-se como orador; especializou-se depois em Finanças. Formou-se em São Paulo em 1883. Foi secretário da Agricultura de Minas e ministro da Fazenda no governo Afonso Pena. Possuía aptidões artísticas: para música e pintura.

8. O texto de Diogo de Vasconcelos foi reproduzido, com introdução e notas de José de Assis Carvalho, sob o título de "História do Áureo Trono", no suplemento Pensar, do Estado de Minas. 28 nov. 1998.

9. Estamos coligindo informações biobibliográficas acerca de todos os autores citados pelos juristas como subsídio para a redação do relatório final da pesquisa sobre as ciências sociais em Minas.

10. Este artigo faz parte de uma série de textos sobre o pensamento social e/ou político produzido em Minas Gerais. Contamos, para isso, com bolsa do CNPq. Expressamos nossos agradecimentos ao apoio dessa instituição.

Abstract. This article deals with the origins of the establishment of the social sciences in Minas Gerais since the forties of this century. It describes the intellectual environment of Ouro Preto in the end of the nineteenth century. The author also analyses texts written by jurists; these texts focus on political ideas and the themes concerned to social theory. It is emphasized the influence from european theoretical trends.

Résumé. Dans l'article il s'agit des antécédents de l'institutionnalisation des sciences sociales à Minas Gerais, survenue depuis des années 1940. Il s'agit aussi bien de la description de l'ambiance intellectuelle de la ville d'Ouro Preto dès la fin du XIXe siècle. Dans la suite, il est question des 
textes des juristes, où il y a l'exposé des idées politiques de l'examen des thèmes en rapport à la théorie sociale. Il rendre évident l'influence des cercles théoriques européens.

\section{Referências bibliográficas}

Arinos, Afonso (1895). "Memória histórica da Faculdade Livre de Direito do Estado de Minas Gerais". Revista da Faculdade, Ouro Preto, a.1, no 2, p. 139 e 179.

BARros, Roque Spencer Maciel (1986). A ilustração brasileira e a idéia de universidade. São Paulo: Convívio/EDUSP.

Barroso, Sabino (1894). "A liberdade". Revista da Faculdade Livre de Direito do Estado de Minas Gerais, Ouro Preto, a.1, p. 85-92.

Barroso, Sebastião Pimenta (1997). Sabino Barroso - um estadista das Gerais. Belo Horizonte: Roma Editora.

Bosı, Alfredo (1974). História concisa da literatura brasileira. São Paulo: Cultrix.

Campista, David Moretzsohn (1901). "O direito público e sua reconstrução científica (Introdução ao estudo do direito público e constitucional)". Revista da Faculdade Livre de Direito do Estado de Minas Gerais, Belo Horizonte, a. VI, p. 57-100.

Chacon, Vamireh (1977). História das idéias sociológicas no Brasil. São Paulo: Grijalto/EDUSP.

DiAs, Fernando Correia (2001). Ouro Preto: território da palavra. Oficina da Inconfidência. Ouro Preto, $\mathrm{n}^{\circ} 1$.

EnCIClopédia Mirador Internacional (1981). São Paulo/Rio de Janeiro: Encyclopaedia Britannica do Brasil Publicações Ltda.

Franco, Afonso Arinos de Melo (1977). Um estadista da República: Afrânio de Melo Franco e seu tempo. Rio de Janeiro: Editora Nova Aguilar.

Franco, Augusto (1906). Estudos e escritos: esboços e crônicas. Belo Horizonte: Imprensa Oficial.

(1904). Fragmentos literários (Crônicas ligeiras). Belo Horizonte: Tipografia Beltrão. 
FrieIro, Eduardo (1955). Páginas de crítica e outros estudos. Belo Horizonte: Editora Itatiaia.

IgLÉSIAS, Francisco (1999). Reedição de Diogo de Vasconcelos. In: Vasconcelos, Diogo. História antiga das Minas Gerais. $4^{\mathrm{a}}$ edição. Belo Horizonte: Editora Itatiaia.

(org.) (1987). Idéias políticas de Pandiá Calógeras. Rio de Janeiro: Fundação Casa de Rui Barbosa.

LABIENo (pseud. Lafayette Rodrigues Pereira) (1934). Vindiciae. O sr. Sílvio Romero crítico e filósofo. Belo Horizonte: Os amigos do Livro.

Lessa, Pedro (1909). Dissertações e polêmicas. Estudos jurídicos. Rio de Janeiro: Tip. do Jornal do comércio. (1925). Reforma constitucional. Rio de Janeiro.

Lima, Augusto de (1894). "Estudos sociais". Revista da Faculdade Livre de Direito de Minas Gerais, Ouro Preto, a I, p. 71-76. (1916). Discursos e conferências. Rio de Janeiro: Tipografia do Jornal do Comércio.

Loво, Estevão (1884). “Do organismo social”. Revista da Faculdade Livre de Direito de Minas Gerais, Ouro Preto, a. 1, p.71-76.

LuCAs, Fábio (1965). Horizontes da crítica. Belo Horizonte: Edições Movimento e Perspectiva.

Monteiro, Norma de Góis (org.) (1994). Dicionário biográfico de Minas Gerais. Período republicano. 1889/1991. Belo Horizonte: Assembléia Legislativa de Minas Gerais. 2 v.

Morais, Rubens Borba \& BerRiEN, William (orgs.) (1999). Manual bibliográfico de estudos brasileiros, (1949). Brasília: Senado Federal - Coleção 500 anos. 2v.

Paim, Antônio (org.) (1981). Plataforma política do positivismo ilustrado. Brasília: Editora da UnB.

Pena, Afonso (1894). "Apresentação". Revista da Faculdade Livre de Direito de Minas Gerais, Ouro Preto, a. 1.

Renault, Delso (1979). Raul Soares de Moura. O professor, o homem de letras, o estadista. Belo Horizonte: Imprensa Oficial. 